\title{
From Seed to Harvest: Growing the Macdonald Campus Seed
}

Library

DANA INGALLS

New Review of Academic Librarianship

\section{Introduction}

The academic library of today is a dynamic, diverse institution, concerned not only with the traditional research and study assistance, but also engaged with the university community. Unusual and innovative collections, technologies, and programmes are widespread, and concern for student wellness is increasingly taken into consideration in libraries. The seed library is one such innovative programme, with the potential for generating user interest and contributing to the wellbeing of students. In 2016, I decided to start a seed library at the Macdonald Campus Library, one of the McGill University library branches. Given the rarity of seed libraries in university libraries (Ingalls, 2017), the process of establishing and then operating the Macdonald Campus Seed Library was an exercise in improvisation, a description of which may prove useful to future seed library innovators. This article will define seed libraries, discuss their history and their role in the context of academic libraries, and the uses they may serve. It will also discuss what is necessary to create a seed library, and offer suggestions and recommendations for the running of such a programme.

\section{Background: Seed libraries}

Some background information on seed libraries, their purposes, and their place in the academic library may be necessary. First, some definition is needed. Seed libraries are often incorrectly conflated with seed banks, which are conceptually similar but practically are quite different. Seed banks exist to preserve the genetic material of both crop species and wild plants as a method of conservation (Eastwood, Cody, Westengen, \& von Bothmer, 2015), and as such are usually housed in facilities equipped with technologically sophisticated equipment designed to ensure proper long-term storage of seeds. Seed libraries differ in both function and facilities. Usually located in public libraries, schools, or community centres (Conner, 2014), seed libraries are a way of providing the community with the means to grow their own food, as well as helping to preserve and disseminate local, rare, or heirloom seed varieties. Almost always a free service, users may "borrow" seeds from the seed library, take them home and grow them, and then (ideally) save some of the seeds from their harvest and "return" them to the seed library. Given this difference in purpose, seed libraries tend to be low-tech, often relying on print inventories and borrowing forms, and run on small or nonexistent budgets, both factors a stark contrast to technologically cutting-edge seed banks. In short, seed libraries are fundamentally community-based, educational programmes, and are thus entirely distinct from seed banks in all but the very broadest sense. They can and should be defined and studied as a separate category of institution.

Seed libraries serve valuable community and educational purposes, regardless of their location or level of funding. While still a relatively new concept-the first seed library was founded in California in 2000 (Conner, 2014) - the philosophy behind them is well-established.

This is an Accepted Manuscript of an article published by Taylor \& Frahcis in New Review of Academic Librarianship on Dec. 18, 2019, available online: http: //www.tandfonline.com/10.1080/13614533.2019.1699838. 
It can be traced the "back to the land" movement that sprung up in North America in the 1960s. Focussing on self-sufficient, sustainable living, these pioneers of modern homesteading were concerned about the rise of agribusiness, the unsustainability of factory farming methods, and the loss of biodiversity in food crops (Jacob, 1997). Part of their solution was not only to plant and grow their own gardens, but also to save seed from those gardens for future crops, seeds which were often traded or given to neighbours and friends. In this way, the seeds for a wealth of food plant varieties abandoned by large growers as unsuitable for industrial agriculture were quietly preserved and maintained by small-scale farmers and gardening enthusiasts.

While the original back to the land movement has faded, its concerns have not, and the seed library is a modern, practical way of addressing these concerns. The focus of seed libraries is generally twofold: providing access and education to users, and supporting diversity and sustainability in local food production. The former is keeping line with the time-honoured mission and purpose of any library, while the latter leans heavily into the realm of sustainability and ecology interests. Given that libraries have in recent decades embraced the sharing economy by creating "libraries of things" (Robison \& Shedd, 2017), with everything from baking pans to power tools available for borrowing, the seed library stands out as a creative fusion of traditional and novel library services.

In any location, a seed library is a valuable tool for education and community outreach. In an academic library, it provides an excellent opportunity to engage with the campus community and to collaborate with student gardening or sustainability groups to host gardening or seed-saving workshops. These types of activities, together with the novelty of a seed library, can generate positive publicity and raise the library's profile in the university community. There is also the opportunity to serve an academic purpose. Seeds can be made available for use in class projects, or in research for a wide variety of subjects, giving the library a new way to support teaching and research at the institution.

Seed libraries also have the potential to contribute to student wellness, an area in which academic libraries are becoming increasingly involved (Hinchliffe \& Wong, 2010). Student welfare has emerged as a growing concern in higher education, and evidence suggests that students can best be supported by employing a holistic approach to their mental and physical health (Ramsey \& Aagard, 2018), involving all areas of university life rather than pigeonholing "wellness" as the sole purview of the student clinic or health centre. Given that students often see the library as a safe, convenient place to study and spend a great deal of time there, library participation in student wellness initiatives makes sense. Some libraries have chosen to transition from a more traditional library arrangement to a learning commons model, designed to integrate library services and resources with spaces which provide students with an optimal learning environment (Holmgren, 2010; Massis, 2010). Library-led student wellness programmes are also increasingly common. Access to therapy animals, "stress-busting" tables with puzzles, colouring pages, or origami paper, and setting up light therapy lamps in study areas, to name just a few examples (Brewerton \& Woolley, 2016; Rose, Godfrey, \& Rose, 2016), are now common at academic libraries in North America. The seed library can fit into this new model, as innovative and potentially beneficial for student wellness, since research indicates 
that gardening can alleviate stress and improve mental health (Jagger, Sperling, \& Inwood, 2016; Mattson, 2009; Soga, Gaston, \& Yamaura, 2016).

\section{The Macdonald Campus Seed Library}

Macdonald Campus is the agricultural campus of McGill University, located on 1600 acres on the western tip of the Island of Montreal, $35 \mathrm{~km}$ from the much larger downtown campus. Home to the Faculty of Agricultural and Environmental Sciences, the School of Human Nutrition, Institute of Parasitology, the McGill School of Environment, and a large working farm, Mac (as it is affectionately known by its 12,000 students, faculty, and staff) forms its own community within the larger world of McGill. There is a great deal of interest in sustainable food systems and food justice among the students and staff of Macdonald Campus, with community gardens, a small market selling produce from the farm, and many student clubs focussed on sustainability, permaculture, and local food movements. This campus culture made it the ideal home for a seed library.

The research and preparation stage of the project was made challenging by the diverse and independent nature of seed libraries. There exist no accepted guidelines for either starting or running such a programme; the fact that there were at the time only a handful of seed libraries are run by academic libraries meant I had few comparable models to work from (more have since been established; see Appendix I for a current list). There were, however, scattershot resources (blog posts, magazine articles, a few books or book chapters) which allowed me to assemble a list of necessary resources to obtain and tasks to be done. The following account of the organisational process is by no means a definitive guide to creating a seed library, but it will discuss the methods I used during the organisational phase, the problems I encountered, the mistakes I made, and the solutions I found.

\section{Legal aspects}

Before starting a seed library, it is vital to ensure that the law is on your side. Depending on the location, there may be little to no legislation that addresses seed libraries specifically, so it can be challenging to ascertain what laws may apply. In general, seed libraries are assumed to fall under laws regarding the distribution of seeds, whether or not such distribution involves monetary exchange. These laws have caused problems for seed libraries in the United States, where state-level laws may be read as prohibiting seed libraries. However, in recent years several states have amended their legislation to explicitly permit seed libraries, while others have concluded that the laws were being incorrectly applied to seed libraries (Sustainable Economies Law Center, 2014). Despite these advances, the situation in many states remains somewhat murky. In Canada, however, the legal status of seed libraries is much less ambiguous. While seed libraries are not explicitly mentioned in the relevant law, the Seeds Act is considered to protect the right to exchange seeds on a small scale (Seeds Act, 1985). In both Canada and the United States, saving or sharing of patented seeds, usually meaning genetically modified seeds, is prohibited as a matter of intellectual property protection (Robison \& Shedd, 2017; The Bauta Family Initiative on Canadian Seed Security, 2014). The Macdonald Campus Seed Library, being located in Canada, is covered under the simpler law, ensuring its right to operate. 


\section{Funding}

One of the extraordinary things about seed libraries is that it is possible to run one on a very tight budget. On the surface, this may seem counterintuative: building a collection of any kind, including seeds, requires substantial funds. This is in addition to the materials for housing the collection and storing the seeds themselves. Fortunately, a culture of enthusiastic sharing of both resources and of ideas exists among seed-savers, so the most costly-seeming component can be obtained at little to no cost. Many seed producers, especially those which concentrate on heirloom and/or non-GMO seeds, will happily donate if asked. These seeds will usually be from the previous year's harvest, since these can no longer be sold, but such seeds will still germinate. If properly stored (in dry conditions, protected from light and extreme heat or cold) most seeds will remain viable for up to five years (Savonen, 2003). In order to acquire seeds by donation, I submitted a request for donation from West Coast Seeds, a British Columbia-based seed company with an established donation programme. I also approached several local farms, one of which, Ferme Tourne-Sol, agreed to donate. With these donations, at an estimated value of $\$ 2000$ CAD, I believed I had sufficient seeds to serve the users. As it turned out, I severely underestimated (a situation I will discuss in more detail in a later section), so in the second year I approached 20 Canadian seed companies with donation requests. 7 of these donated, providing a quantity of seeds that was more than sufficient for the users' needs, at an estimated value of $\$ 4,250$ CAD. The only cost to the library was shipping fees, which were minimal (\$10 in the first year, $\$ 42$ in the second).

Many other materials can also be found at low or no cost, including housing for the seed collection and organisational materials (such as envelopes to hold the seeds). By fortuitous coincidence, the drawers of a card catalogue cabinet are perfectly proportioned to hold a standard-size seed packet. Although the McGill Library transitioned to electronic catalogues decades ago, a few cabinets remained in storage. One such cabinet, a beautiful classic item made of solid wood with steel hardware, was found in perfect condition wedged in the far corner of a basement. A quick cleaning was all that was needed to ready it for its new job as a seed library. In the interests of further cost-saving, I made seed packets using a stash of unwanted letter-size envelopes which had been printed with an error in the library's return address. While this was certainly cheap, and very much is the spirit of sustainability, I do not recommend doing this, as it was extremely time-consuming. Once I ran out of handmade envelopes, I ordered envelopes of the type used to hold small change, which are the same size as a seed packet. These were of course not free, but they were inexpensive enough, at \$30 CAD for a box of 1000, to fit into the Seed Library's small budget.

There was, however, a need for some funding. The cabinet, being solid wood, was very heavy and required a custom-built stand to hold it. I also wanted to build a collection of supporting resources for the seed library: books on seed-saving, gardening, composting, and home food preservation. Then there were the promotional materials, including informational bookmarks, a sign to advertise the seed library's location, the costs associated with the opening event I hoped would generate interest in the new programme, and the aforementioned shipping costs and seed envelopes. Since many of these were one-time expenses, I applied for and received a grant through the library's Innovation Fund, which provides seed money (as it 
were) for innovative programmes and technologies in the McGill Library. This grant covered all the initial expenses, as well as the recurring costs for the first two years. Thereafter, on the strength of the seed library's success, I requested and received a yearly budget to cover ongoing expenses. These expenses remain minimal, and I am able to continue running the programme on a budget of $\$ 200$ CAD per year.

\section{Organisation \& borrowing}

There is no single accepted system for cataloguing seeds, although many methods are used by various seed libraries. These range from simple alphabetical organisation or a classification system based on ease of growing, to a more complex method using botanical names (Conner, 2014; Seed Library Network, 2018). I briefly considered using this latter method, thinking that this science-focussed organisational system might appeal to users at Macdonald Campus. However, the seed library would be open to all McGill community members, many of whom would not be in the sciences, so in the interest of making the system as accessible for all users, I chose a more basic alphabetical system. This system consists of three levels, the first being simple division of seeds into the Flowers, Herbs, or Vegetables categories. Within each category, seeds are further classified by common type (Corn, Lettuce, Squash-Summer, Squash-Winter, etc.) and then organised alphabetically by variety (SquashWinter: Delicata, Golden Hubbard, Red Kuri, Spaghetti, Sweet Dumpling...). This system mimics the organisational method commonly used by seed catalogues, so it is familiar to gardeners, and is simple enough to allow any novice to immediately understand and use it. Each seed variety was given a record with the seed's common and scientific name, a description of the seed, and basic growing information. To convey as much information as possible in a minimum of space, I also created a system of icons to indicate certain common characteristics, such as a flowerpot to indicate that the plant can be grown in containers.

The organisational as well as the borrowing schema was by necessity separate from the main library system. The only exception to this was the print collection associated with the seed library, which was added to the library system as with any other purchase, and given a new subcollection heading. The catalogue used by the McGill Library, WorldCat, is not customisable on the level that would be needed to integrate records for an ever-changing seed collection. The library website, however, is very flexible. To create the pages I needed, I worked with the library's Web Support Consultant, who was able to build pages to my specifications. The "catalogue", a browsable and sortable (but not searchable) page was populated with the seed records, allowing users to view the seed collection, and allowing me to update it whenever necessary. Also available on the website are a LibGuide, and the registration and seed request forms. The latter is important for accessibility; I was initially concerned about the access barrier posed by Macdonald Campus's isolation from the much larger downtown campus. The request form allows users to request seeds and have them sent to the library of their choice, using the existing inter-branch delivery system.

The borrowing system was also separate from the existing library system, again due to logistical considerations. It was not practical to affix barcodes to each seed packet so they might be "checked out" in the same way as any other library item, nor would it be particularly 
useful since the seeds were not in the main catalogue anyway. Borrowing is therefore done using paper forms which users fill out, noting what they have taken. Users may also request seeds from the catalogue using an online form, which is sent to the Seed Library email account where I retrieve and process them; however, this is also unconnected to their library account. This system works because I do not find it important to keep track of who has what, since unlike most library holdings, they have no due date, and users will not be returning the items in the condition in which they borrowed them. It exists mainly to allow me to keep track of our seed stocks so I can keep the inventory up to date.

Borrowing is restricted to McGill users (which includes current students, faculty and their spouses, staff, alumni, and community members who have purchased a McGill Library membership) in an effort to keep loans at a manageable level. Initially, I set no restrictions on the number of seed packets a single user may borrow, simply asking users to take only what they personally would use. This honour system worked well for the first year, until in the second year a user attempted to borrow 105 packets, which he apparently planned to supply to many members of his family. After this event, I imposed a limit of 25 packets per person. There are, however, exceptions for individuals who wish to use seeds for research or other universityrelated projects.

\section{Promotion \& launch}

With any new library offering, it is important both to make the target population (in this case, the entire university community) aware of the programme's existence, and to market it so they understand how it can benefit them (Solomon, 2016). Since the Seed Library was unlike any other programme currently available at the library, it was also important to educate users on what exactly it was. The literature indicates that such promotion is most effective when multiple techniques are used $(\mathrm{Yi}, 2016)$ and when it is presented repeatedly rather than a single time (Duke \& Tucker, 2007), so I employed a variety of promotional approaches over the course of six months prior to the Seed Library's opening day. In this I had the help of the Library Communication Officer, who was enthusiastic about the Seed Library's potential for attracting positive publicity for the McGill Library. She designed a simple but striking logo for the seed library, and disseminated promotional materials to university outlets beyond the library, from the Alumni Association to the university newspaper.

For orientation in late August and early September, I created bookmark-sized fliers advertising the impending seed library and offering a short explanation of the concept. These were handed out at library orientation events along with other informational library materials. In October, I arranged for an experienced seed saver from Ferme Tourne-sol, one of our donors, to come to campus and teach a seed saving workshop, giving me an opportunity to promote the seed library. A month before the opening, in February, I submitted a notice to the newsletters of the undergraduate and graduate student societies at Macdonald Campus, to the campus listserv, and posted on the various social media accounts associated with the McGill Library and Macdonald Campus. On the opening date (March 20, the first day of spring), the library hosted a Grand Opening event, offering refreshments and a drawing for prizes, in addition to displaying the Seed Library itself. The event was well-received, drawing 
approximately 300 students, faculty, and staff (of whom nearly 200 registered on the spot). I believe this event was instrumental in boosting the popularity of the Seed Library, grabbing users' attention immediately and setting up an ideal situation for news of the new programme to spread by word of mouth.

Since the Seed Library's opening, promotion has continued via social media, the Seed Library mailing list, materials available at library events, and unexpectedly, interest from media both inside and outside the university. The university newspaper, the McGill Reporter, covered the opening event, and the Seed Library was featured in a spot on CTV Montreal a year later. Most recently, an article was published in the magazine Panoram Italia, and I was interviewed on the CBC Radio Montréal programme Let's Go. These promotional windfalls have helped to periodically boost knowledge of the Seed Library in the McGill community.

\section{The seed library as outreach tool}

Seed libraries can be a powerful tool for connecting the library to the community, and the Macdonald Campus Seed Library has been successful in this regard. As part of the Seed Library's mission to provide education for its users, we have offered workshops on topics such as garden planning, seed starting, seed saving, and home canning. Not only are these workshops (all of which have been well attended by both students and faculty) interesting and unusual outreach in and of themselves, they have also been opportunities to connect and collaborate with members of the university community. Some workshops, such as the seed-starting, garden planning, and seed-saving workshops, have been co-hosted by the Seed Library and two student groups, the Macdonald Student-run Ecological Gardens and the Macdonald Permaculture Club, organisations which share similar interests with the Seed Library. We have also established a seed exchange with the Permaculture Club, an arrangement which is mutually beneficial and helps further the Seed Library's mission. The home canning workshop was made possible with help, both logistical and informational, from the Department of Food Science. These connections both spread knowledge of the Seed Library, and enhance the McGill Library's profile in the university community, making the library more visible and demonstrating our commitment to innovation in our offerings.

We have also had opportunity to connect with people beyond the McGill community. Most notably, I served as an informal advisor to a local food justice organisation, Santropol Roulante, as they went through the process of starting their own seed library. It was gratifying to be able to offer both advice and seeds from our collection to help them start a seed library that would serve Montreal's urban gardeners. We have also participated in seed exchanges with another seed library, located in a local public library, and with a small farm and seed producer in another province. This type of knowledge and resource exchange is at the heart of the seed library philosophy, and as the caretaker of a seed library it is an important that I seek out opportunities to engage in such exchanges.

\section{Challenges \& solutions}


In the course of the Seed Library's nearly two years of operation, problems predictably arose from time to time. Some of these were anticipated, allowing me to plan solutions in advance, while others were unexpected and had to be solved on the fly. Among the former was a more philosophical issue which may be unique to those seed libraries which are located at academic institutions. Many seed libraries choose to take the Safe Seed Pledge (Council for Responsible Genetics, 1999), which among other things expresses opposition for the genetic engineering of food crops. This attitude towards genetically engineered organisms (GMOs) is prevalent in the seed-saving community, but constitutes a potentially fraught political issue in the context of a university library serving academic departments whose research may include genetic engineering. In considering this issue, I came to the conclusion that nothing about the Seed Library's mission is in opposition to genetic engineering as a scientific endeavour (and in any case, no seeds in the Seed Library are genetically engineered, for the legal reasons mentioned previously). For this reason, as well as wanting to maintain good relations with the university's scientists, I chose to refrain from explicitly associating the Seed Library with the issue of GMOs.

The unexpected problems were generally of a more logistical nature. The first to arise was an issue with our seed stocks; namely, I had underestimated how many seeds we would need to meet demand. The Seed Library was immediately far more popular than I had anticipated, resulting in a collection that quickly dwindled to nothing (the Seed Library opened with 449 packets of seeds, which by the end of the first week had decreased to 62 packets, all of which were gone by the end of the second week). I realised within a few days that I would need to restock, but it still took a couple of weeks for the new seeds to arrive and for me to process them for addition to the collection, leaving the Seed Library briefly empty and some users unhappy. I also had to purchase these seeds, which ate up a considerable portion of my budget. After this experience, I was able to plan better for the second year. I solicited more companies for donations, giving us seven donors as opposed to the first year's two, which resulted in a more than adequate seed supply with which to begin the 2018 growing year.

\section{Statistics}

I kept track of Seed Library statistics from the beginning, and this careful record-keeping provides valuable data on who is using the Seed Library, when, and how they are using it. This information allows me to identify patterns and better predict usage, and to understand our user demographics. An analysis of the number of discrete borrowing instances between March 2017 and December 2018 reveals a clear pattern (Figure 1). This borrowing pattern will be different for different seed libraries (it is largely dependant on the climate and how it affects the growing season; people in Quebec will borrow seeds to start indoors from late February to early April, whereas a seed library located in a warmer climate might see their borrowing spike slightly later, since a long indoor head start for seedlings may not be required). Knowing this predictable rise and fall in borrowing, I am able to prepare in advance, ensuring that the Seed Library is restocked, staff are reminded of borrowing procedures, and the catalogue is updated. The statistics also show that the majority of seed loans are requested via the online form, rather than in person in the library. These loans are processed by me and on high volume days can take up to 30 minutes a day to fulfil, so I am able to plan ahead and build the necessary 
time into my day during the high season of March and April. This advance knowledge is crucial for my time management.

Figure 1. Borrowing statistics for the Macdonald Campus Seed Library.

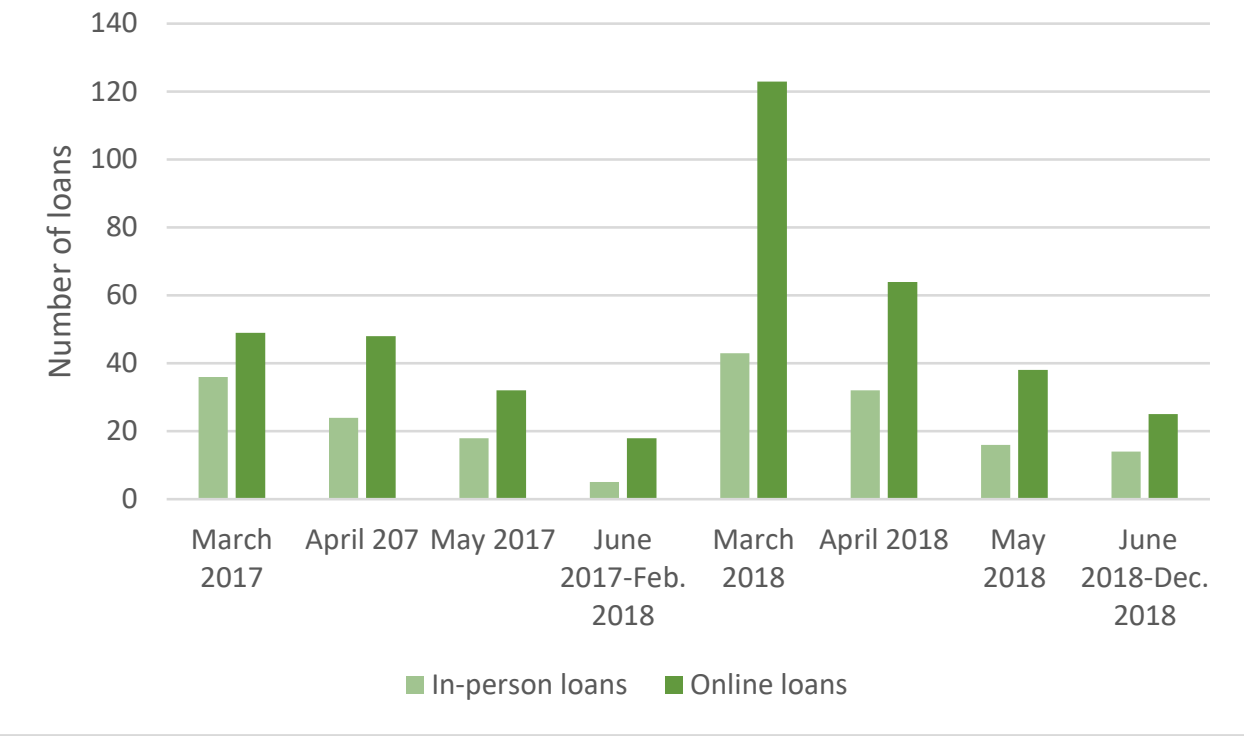

Statistics on the demographics of our users also provides useful information. As of December 2018, the Seed Library has 524 registered users, the majority of whom are students (Figure 2).

Figure 2. Registered users of the Macdonald Campus Seed Library.

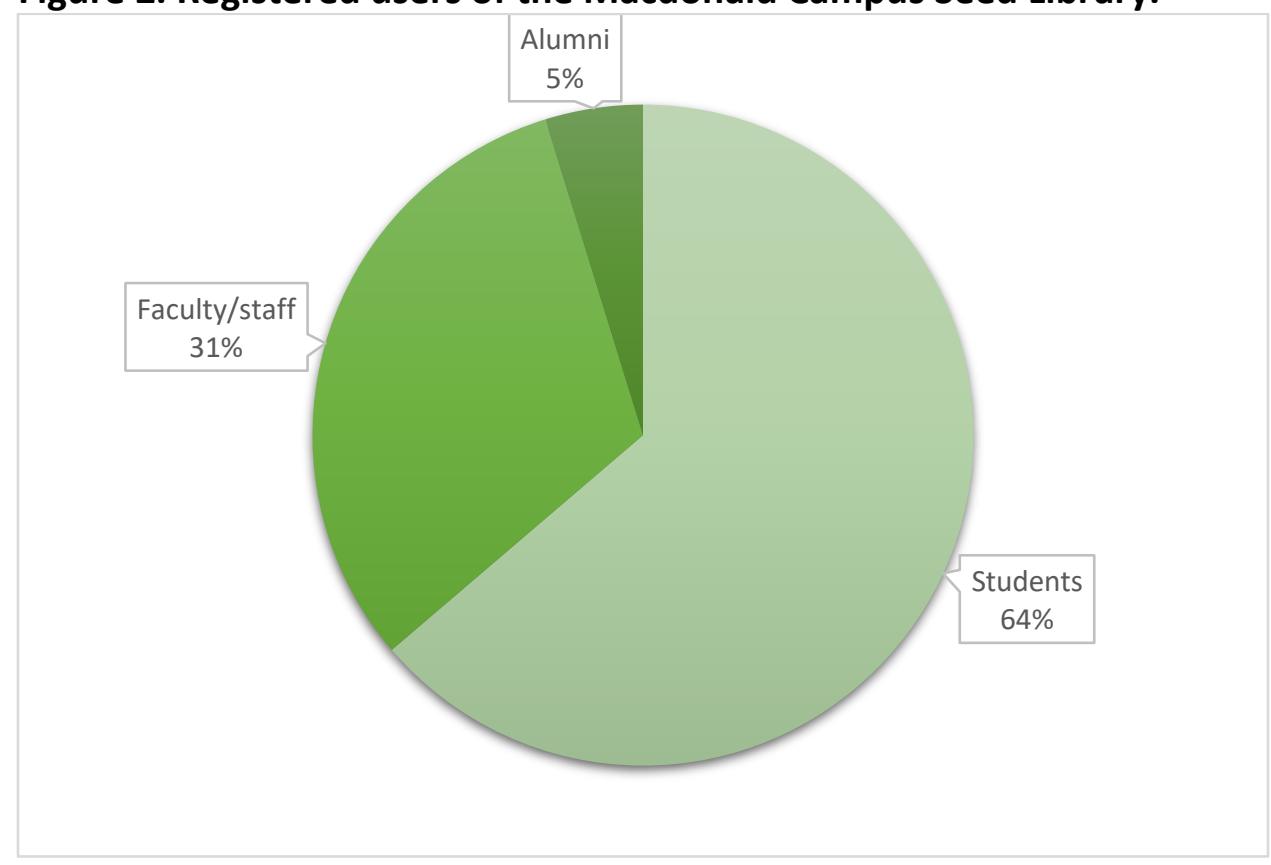

Certain assumptions can reasonably be made about student users: most will have minimal garden space (students at McGill, especially undergraduates, generally live in residence 
halls or small city apartments with little to no outdoor space) and that they will not have a lot of disposable income to spend on gardening supplies. Since I know that students constitute well over half of Seed Library users, I try to ensure that our collection includes seeds which will grow in containers or even indoors (as discussed previously, since the Seed Library's collection comes primarily from donations, I have minimal control over what goes into it, but I do communicate our users' needs to donors). Our supporting collection is also heavy on resources for student users, with books on container, small space, and indoor gardening, and information on using inexpensive or free materials to make necessary garden supplies, how to cleanly compost indoors, and other information helpful to people living in small urban spaces.

\section{Suggestions for starting a seed library}

A definitive step-by-step guide on starting a seed library would be difficult to assemble, due to the diversity of locations, spaces, and circumstances in which academic libraries operate. However, based on both the literature and my own experiences, I can offer some suggestions for the potential seed librarian, which I believe will be applicable in most if not all academic libraries.

- Ensure that operating a seed library is legal in your jurisdiction, and that you understand any restrictions that may exist regarding seed sharing or seed saving.

- Know your budget. Look into sources of funding, such as departmental grants, and then budget carefully for what you need. Be sure to leave some spare funds for unanticipated expenses.

- Find sources for seeds. Approach local farms that sell seeds, or seed companies which focus on heirloom seeds, and offer to pay for shipping if possible. This should be done well in advance of the growing season, in late autumn or early winter. It may seem early, but seed suppliers often get donation requests, and may run out of seeds. It will also give you time to process new seeds for inclusion in your seed library.

- Establish your cataloguing/organisation system, and your borrowing and return methods. As discussed earlier, there are a great variety of methods to choose from, the selection of which will depend heavily on the institution.

- Set your seed library use rules. Who can use the seed library? How many seeds/seed packets are users permitted to borrow?

- Create a collection of resources to support users of the seed library-resources on seed starting, pest control, container or small-space gardening, seed saving, and general gardening guides are important to help users make the most of their seeds. If your budget permits, you may wish to purchase books as part of this collection; if not, there are a wealth of free gardening resources available online. A comprehensive LibGuide or similar digital/open access resource list can be assembled at no cost.

- Prepare promotional materials (such as bookmarks or postcards) that briefly explain what a seed library is and how it is used. Many, if not most, users will be unfamiliar with the concept, and such materials can serve both as an introduction to the programme, and as promotional items.

- When you are ready to launch your seed library, host an opening event for your user community. This is an excellent way to promote your seed library, educate people on 
the concept, and draw in new users. If your budget allows, offering refreshments, activities (such as seeds saving demonstrations), and giveaways or prizes are good additions to a seed library opening event.

\section{Conclusion}

The process of creating and learning to run the Macdonald Campus Seed Library has been remarkable. It has been a constant learning experience, both for me and for our users. While it is a more time-consuming programme than I initially anticipated, its value as a community engagement tool has proved to be correspondingly exceptional. User response has been overwhelmingly positive, and the publicity from both inside and outside the McGill community has been beneficial for the overall perception of the Library as an exciting, dynamic part of the university. It has facilitated connections and collaborations between the Library and student groups, faculty, and alumni, helping the Macdonald Campus Library become a more visible part of campus life.

As of this writing, little scholarly attention has been paid to the topic of seed libraries, especially in university libraries. Further research into this topic would be valuable to practitioners in public service roles; it would be interesting, for instance, to look at seed libraries' impact on student wellness, both mental and physical, or at ways in which seed libraries might support or assist with research or university or community sustainability initiatives. More discussion of the process of starting and operating a seed library in an academic context would also be worthwhile, since most information on this topic concerns seed libraries in public or school libraries, some of which is inapplicable in a university library context.

The Macdonald Campus Seed Library fulfils a particular niche in the slate of innovative library programmes at McGill: an exciting and unusual attraction for users, a source of specialised information and physical resources, a catalyst for new connections between the library and diverse groups within the McGill community. It is a relatively inexpensive programme, and once established, requires only a minimal time commitment to maintain; given these factors, I have concluded that it is a programme that serves its users well, and is worth continuing for the foreseeable future.

\section{References}

Brewerton, A., \& Woolley, R. (2016). Study Happy: Library wellbeing initiatives from the University of Warwick. SCONUL Focus, 68, 15-25.

Conner, C. (2014). Seed libraries: And other means of keeping seeds in the hands of the people. Gabriola Island, BC: New Society Publishers.

Duke, L. M., \& Tucker, T. (2007). How to develop a marketing plan for an academic library. Technical Services Quarterly, 25(1), 51-68. doi:10.1300/J124v25n01_05 
Eastwood, R. J., Cody, S., Westengen, O. T., \& von Bothmer, R. (2015). Conservation roles of the Millennium Seed Bank and the Svalbard Global Seed Vault. In R. J. Redden (Ed.), Crop wild relatives and climate change. Hoboken, NJ: Wiley-Blackwell.

Hinchliffe, L. J., \& Wong, M. A. (2010). From services-centered to student-centered: A “Wellness Wheel" approach to developing the library as an integrative learning commons. College \& Undergraduate Libraries, 17(2-3), 213-224. doi:10.1080/10691316.2010.490772

Holmgren, R. A. (2010). Learning commons: A learning-centered library design. College \& Undergraduate Libraries, 17(2-3), 177-191. doi:10.1080/10691316.2010.4815

Ingalls, D. (2017). Breaking new ground: The case for seed libraries in the academic library. Public Services Quarterly, 13(2), 78-89. doi:10.1080/15228959.2017.1304315

Jacob, J. (1997). New pioneers: The back-to-the-land movement and the search for a sustainable future. University Park, PA: Pennsylvania State University Press.

Jagger, S., Sperling, E., \& Inwood, H. (2016). What's growing on here? Garden-based pedagogy in a concrete jungle. Environmental Education Research, 22(2), 271-287. doi:10.1080/13504622.2014.997195

Massis, B. (2010). The academic library becomes the academic learning commons. New Library World, 111(3/4), 161-163. doi:10.1108/03074801011027664

Mattson, R. (2009). Biofeedback evidence of social and psychological health benefits provided by plants and flowers in urban environments. Acta Horticulturae, 88, 751-757. doi:10.17660/ActaHortic.2010.881.124

Ramsey, E., \& Aagard, M. C. (2018). Academic libraries as active contributors to student wellness. College \& Undergraduate Libraries, 25(4), 328-334. doi:10.1080/10691316.2018.1517433

Robison, M., \& Shedd, L. (2017). Audio recorders to zucchini seeds: Building a library of things. Santa Barbara, CA: Libraries Unlimited.

Rose, C., Godfrey, K., \& Rose, K. (2016). Supporting student wellness: "De-stressing" initiatives at Memorial University Libraries. Partnership: The Canadian Journal of Library and Information Practice and Research, 10(2), 1-21. doi:10.21083/partnership.v10i2.3564

Savonen, C. (2003). How long do garden seeds last? Retrieved from https://archive.extension.oregonstate.edu/gardening/how-long-do-garden-seeds-last

Seed Library Network. (2018). How to organize your seeds. Retrieved from http://seedlibraries.weebly.com/how-toorganize-your-seeds.html 
Soga, M., Gaston, K. J., \& Yamaura, Y. (2016). Gardening is beneficial for health: A metaanalysis. Preventive Medicine Reports, 5, 92-99. doi:10.1016/j.pmedr.2016.11.007

Solomon, L. (2016). The librarian's Nitty-Gritty guide to content marketing. Chicago, IL: ALA editions, an imprint of the American Library Association.

Sustainable Economies Law Center. (2014). Protecting the seed commons. Retrieved from https://www.theselc.org/save_seed_sharing

The Bauta Family Initiative on Canadian Seed Security. (2014). Seed policy in Canada. Retrieved from http://www.seedsecurity.ca/doc/Seed_Policy_Discussion-EN.pdf

Yi, Z. (2016). Effective techniques for the promotion of library services and resources. Information Research: An International Electronic Journal, 21(1), 777-780.

\section{Appendix I: Seed libraries in academic libraries in the United States and Canada}

I have included in this list all seed libraries located in academic libraries in four-year colleges and universities in the United States and Canada. I have excluded for-profit institutions, and two-year institutions, such as community colleges (in the United States) and colleges and CEGEPs (in Canada). I have also excluded seed libraries not run by academic libraries; other universities have seed libraries which are maintained by student groups or agricultural extension stations rather than by the university's library. The number of seed libraries in academic libraries has more than doubled since I last conducted this search in 2016, perhaps indicating a growing interest in this area among academic librarians.

\section{Canada}

- Dalhousie University, Halifax, Nova Scotia (http://seedlending.library.dal.ca/)

- Kwatlen Polytechnic University, Surrey, British Columbia (http://libguides.kpu.ca/seeds)

- McGill University, Montréal, Québec (https://www.mcgill.ca/library/branches/macdonald/seed-library)

- University of British Columbia, Vancouver, British Columbia (https://guides.library.ubc.ca/seedlendinglibrary)

- University of Ontario Institute of Technology, Oshawa, Ontario (https://guides.library.uoit.ca/seedexchange)

- University of Toronto, Toronto, Ontario (https://utsc.library.utoronto.ca/seed-library)

\section{United States}

- Adams State University, Alamosa, Colorado (https://libguides.adams.edu/seedtoseed)

- Arizona State University, Tempe, Arizona (https://libguides.asu.edu/seedlibrary)

- Auburn University, Auburn, Alabama (https://auburnseedlibrary.wixsite.com/falllineseedlibrary)

- Bennington College, Bennington, Vermont (https://libraryguides.bennington.edu/seeds)

- Daytona State College, Daytona Beach, Florida (https://library.daytonastate.edu/seeds) 
- Georgia Southern University, Statesboro, Georgia

(https://library.georgiasouthern.edu/seeds/)

- Hampshire College, Amherst, Massachusetts

(http://libguides.hampshire.edu/seedlendinglibrary)

- Indiana University, Bloomington, Indiana (https://libraries.indiana.edu/seed-libraryprogramme)

- Indiana University-Purdue University Indianapolis, Indianapolis, Indiana

(https://iupui.libguides.com/seedlibrary)

- Marywood University, Scranton, Pennsylvania

(https://marywoodseedlibrary.wordpress.com/)

- University of California Los Angeles, Los Angeles, California

(https://clarklibrary.ucla.edu/visit/seed-catalogue)

- University of Arizona, Tucson, Arizona (https://new.library.arizona.edu/seed-library)

- University of Maine at Augusta, Augusta, Maine (https://mycampus.maine.edu/web/uclibrary-portal/uma-seed-library)

- University of Massachusetts Amherst, Amherst, Massachusetts (https://guides.library.umass.edu/seedlibrary)

- University of North Carolina at Asheville, Asheville, North Carolina (https://library.unca.edu/seeds)

- University of San Francisco, San Francisco, California (https://guides.usfca.edu/seeds)

- University of Tennessee, Knoxville, Tennessee (https://libguides.utk.edu/seedlibrary)

- Wells College, Aurora, New York (https://www.wells.edu/news/2017/01/19/wellscommunity-seedlibrary-open-2017) 